\title{
A longitudinal analysis for informativeness of earnings announcements in Borsa Istanbul
}

Informativeness of earnings announcements

\author{
Aykut Ahlatcioglu and Nesrin Okay \\ Department of Management, Bogazici Universitesi, Istanbul, Turkey
}

\begin{abstract}
Purpose - The purpose of this paper is to assess the information value of earnings announcements for the 2007-2017 period in Borsa Istanbul.

Design/methodology/approach - Abnormal volatility (AVOL) and abnormal absolute return (AAR) in the three-day window around the earnings announcement are used as proxies for information content. A pooled regression of AVOL and AAR is conducted to test for the existence of information content and analyze its time trend along with its determinants.

Findings - The authors find significantly positive AVOL and AAR which shows that earnings have information content for investors during the sample period. Furthermore, both proxies demonstrate a positive time trend after controlling for various firm characteristics and surprise measures. The authors take this as evidence that overall informativeness of earnings has increased over time. The authors observe that this increase is most prevalent for growth companies and earnings announcements with high absolute surprise. This study provides partial support for the hypothesis that value of earnings announcements has increased after an improvement in information dissemination technology with the inception of the online disclosure platform, KAP.

Practical implications - Understanding information value of earnings announcements is of interest for companies which prepare earnings reports, regulators who set standards on their content and frequency and investors which make investment decisions based on information released at these announcements.

Originality/value - There had been few non-US studies related to information value of earnings announcements. The overwhelming majority of these are conducted using limited data sets from the latter part of the last century and only analyze annual earnings announcements. The authors aim to shed light on the subject using a broad and recent sample of quarterly earnings announcements from a major emerging market, Turkey.
\end{abstract}

Keywords Event studies, Information and market efficiency, International financial markets

Paper type Research paper

\section{Introduction}

Earnings announcements are the main scheduled and periodic corporate announcement for listed firms in a stock market as they provide a wealth of financial and operational information with regard to the latest fiscal period. As such, an analysis of whether these announcements are valuable in terms of their content is of interest for companies, investors as well as regulatory bodies. Beaver (1968) was the first to empirically examine the information content of earnings announcements. From a valuation point of view, an earnings announcement could be considered to have information if it leads to change in market participants' expectation for future returns. Accordingly, Beaver (1968) used abnormal volatility and abnormal volume at the time of announcement as gauges for information value as the former reflects the resulting change in expectations of the market as a whole while the former reflects changes in the expectation of individual investors. Landsman and Maydew (2002) used similar proxies to those

(C) Aykut Ahlatcioglu and Nesrin Okay. Published in Journal of Capital Markets Studies. Published by Emerald Publishing Limited. This article is published under the Creative Commons Attribution (CC BY 4.0) licence. Anyone may reproduce, distribute, translate and create derivative works of this article (for both commercial and non-commercial purposes), subject to full attribution to the original publication and authors. The full terms of this licence may be seen at http://creativecommons.org/licences/by/4.0/legalcode

Received 13 September 2019 Revised 15 September 2019 Accepted 17 September 2019 
JCMS

3,2

180

in Beaver (1968) for information content and concluded that there is an increase in the informativeness of quarterly earnings reports in the USA for the 1972-1998 period.

The non-US evidence on information content had been scarce and mostly conducted with limited data sets using only annual earnings announcements. Also, the samples used are not recent and accordingly do not reflect the changes in market structure in the last two decades such as the emergence of algorithmic trading. In this study, we empirically look at whether quarterly earnings announcements have information content and how the informativeness of these announcements has changed over the 2007-2017 using a broad sample comprised of over 12,000 observations coming from 396 companies listed at Borsa Istanbul, the sole stock exchange in Turkey. As proxies for information content, we use abnormal volume (AVOL) and abnormal absolute return (AAR) around earnings announcements defined similar to Dellavigna and Pollet (2009) and Asthana and Balsam (2001), respectively. We find significant information content at earnings announcements for our sample period with average AVOL and average AAR both greater than 0. Comparing annual earnings announcements with interim earnings announcements, we observe a higher AVOL, but lower AAR at annual announcements. Therefore, our findings do not suggest that annual earnings announcements are more informative than the interim earnings announcements. In line with Landsman and Maydew (2002), we find a positive time trend in both AVOL and AVAR even after controlling for firm characteristics such as size, book-to-market and beta as well as the magnitude and direction of surprise. This implies that the informativeness of earnings has increased at Borsa Istanbul and this is not solely attributable to change in firm composition over time. Our regression analysis also shows that this time trend is more pronounced for growth companies and earnings announcements with a greater magnitude of surprise.

Looking at several drivers of the observed increasing trend in the information content of earnings announcements, Francis et al. (2002) singled out over-time expansion in concurrent information such as issuance of operational guidance as the main driver among them. Although we think this could be a plausible explanation for the positive trend in earnings informativeness in Borsa Istanbul, a full-blown analysis similar to Francis et al. (2002) is beyond the scope of this paper. However, we examined whether the introduction of the public disclosure platform (KAP) has made earnings announcements more valuable for investors as evidenced by a stronger market reaction. The KAP is an online platform similar to EDGAR in the USA at which companies are required to disclose all material corporate announcements first before other communication channels. KAP which was introduced in June 2009 replaced a paper-based heavily manual process at which companies send relevant information to the Borsa Istanbul through fax (see Mugaloglu and Erdag, 2011 for more detail). Hence, it could be argued that KAP helped democratize the information environment by allowing market participants to access material corporate information with no delay and with no cost. To reduce the effect of potentially confounding events, we analyze the impact of KAP on a sub-sample which consists of observations with earnings announcements made between one year before the KAP introduction and one year after the $\mathrm{KAP}$ introduction. We find that the AAR is higher in the post-KAP period (June 2009-May 2010) compared to pre-KAP period (June 2008-May 2009), but there is no similar significantly positive change for AVOL. Accordingly, our results are not conclusive on whether a significant change in the information dissemination technology had an impact on the informativeness of earnings announcements.

\section{Literature review}

Using a US sample of 506 annual earnings announcements for the 1961-1965 period, Beaver (1968) established that earnings announcements have information content as evidenced by significant abnormal volume and abnormal volatility around earning announcement dates. 
Following this seminal work, several studies with more extensive data sets and different methodologies such as Morse (1981), Kiger (1972), Bamber (1986) and Ziebart (1990) reached similar conclusions on the information content of earnings. A related research question is how the informativeness of earnings announcements has evolved over time. Using a broad sample of 92,613 firm-quarter observations for the 1972-1998 period, Landsman and Maydew (2002) found that the magnitude of abnormal volume and volatility increased over time which they took as evidence of increased informativeness of earnings announcements. Francis et al. (2002) look at three different explanations for Landsman and Maydew's (2002) finding of increased information content of earnings. These are increase in the absolute amount of unexpected earnings conveyed in the announcements, increase in the intensity of investors' average reaction to unexpected earnings and increase in the amount of information released at earnings announcements. Their findings do no support the first two explanations and they conclude that the observed increase in information content is driven by the over-time expansion in the amount of concurrent information disclosed in firms' earnings announcements. In particular, they find that the length of earnings announcement press release grew from an average of 517 words in 1980 to 2,427 words in 1999 while disclosure of detailed income statement grew monotonically from 8.5 to 77.8 percent. Collins et al. (2009) confirm that expansion in the amount of concurrent information disclosed by firms is a driver of increase in information content. However, they also find that the market's increased reliance on non-GAAP Street earnings which are typically disseminated concurrently with firms' earnings announcements by analyst estimate clearinghouses such as IBES is also a factor in explaining informativeness.

The international evidence on the information value of earnings is scarce compared to the evidence for the USA. Earlier work which utilized relatively limited data sets such as Odabasi (1998) for Turkey, Rippington and Taffler (1995) for the UK, Pellicer and Rees (1999) for Spain, Gajewski and Quéré (2001) for France and Sponholtz (2008) for Denmark is supportive of the hypothesis that earnings announcements have information content, but their sample sizes do not allow for an extensive cross-sectional or temporal analysis of information content. A more recent and comprehensive study is DeFond et al. (2007) which analyzes over 50,000 annual earnings announcements in 26 countries for the period 1995 through 2002. They measure the information content of earnings announcements as the two-day abnormal return variance around earnings announcement and show that the information content is higher for countries with higher quality earnings, stronger enforcement of insider trading laws, more frequent interim financial reporting and greater financial disclosure. Truong (2012) analyzes the information content of earnings announcement in New Zealand for the period 1994-2009 using a sample of more than 2,500 semi-annual earnings announcements. He finds that the information content of earnings announcements as measured by abnormal volume and abnormal volatility has increased significantly over time for both interim and preliminary earnings announcements. Truong (2012) also tests the relation between the adoption of International Financial Reporting Standards (IFRS) and the information content of earnings announcements and shows that the information content of earnings announcements increases considerably in the post-IFRS adoption period in New Zealand. Truong (2012) argued that this is consistent with the view that the IFRS adoption improved the quality of accounting information and partly explains the rising trend in the information content of earnings announcements.

\section{Variables and sample selection}

\subsection{Defining measures for information content of earnings announcements}

We use abnormal volume (AVOL) and abnormal absolute return (AAR) as measures to proxy information content of earnings announcements. We define AVOL for firm $i$ in quarter $q$ similar to Dellavigna and Pollet (2009) as the difference between the average log trading volume during the announcement window $[t-1, t+1]$ and the average log trading 
JCMS

3,2

182

volume during the non-announcement period [t-60,t-11] (see (1a)). On the other hand, we define AAR similar to Asthana and Balsam (2001) as the difference between the average absolute value of daily return during the announcement window $[t-1, t+1]$ and the average absolute value of daily return during the non-announcement period of $[t-60, t-11]$ normalized by the standard deviation of absolute return during the non-announcement period (see (1b)). When constructing both abnormal volume and abnormal volatility, $[t-10$, $t-2]$ window is intentionally excluded from the non-announcement period to avoid the impact of any market activity in anticipation of the upcoming earnings report:

$$
\begin{gathered}
\operatorname{AVOL}_{i, q}=\frac{1}{3} \sum_{k=t-1}^{t+1}\left(\log \left(V_{i, k}\right)\right)-\frac{1}{50} \sum_{k=t-60}^{t-11}\left(\log \left(V_{i, k}\right)\right), \\
\operatorname{AAR}_{i, q}=\frac{(1 / 3) \sum_{k=t-1}^{t+1}\left(\left|R_{i, k}\right|\right)-(1 / 50) \sum_{k=t-60}^{t-11}\left(\left|R_{i, k}\right|\right)}{\sigma_{\left|R_{i, k}\right|}} .
\end{gathered}
$$

\subsection{Explanatory variables}

Time trend. In order to examine how AVOL and AAR at earnings announcements change over time, we define a time trend variable, TIME which is incremented by 1 for each month in the sample period, taking values ranging from 1 to 133.

Annual earnings indicator. The amount of information content of interim earnings announcements could differ from the level of information at annual/fourth quarter earnings announcements as extensively discussed at Basu et al. (2002). In order to account for this difference, we introduce a binary variable ANDUM which takes a value of 1 if the announcement is a fourth quarter/annual earnings announcement and 0 if the announcement is an interim earnings announcement.

Absolute value and direction of surprise. Consistent with Kim and Verrecchia's (1991) model, Bamber (1987) found that there is a positive correlation between abnormal trading volume at earnings announcements and the absolute magnitude of earnings surprise. Accordingly, we include the absolute value of unexpected earnings as an explanatory variable as in Landsman and Maydew (2002) and Truong (2012). The variable IUEI is constructed for a given security $i$ in quarter $q$ as in Equation (2) by dividing the absolute value of the difference between the reported net profit for the current quarter and its value in $q-4$ by the value of market cap at the end of quarter $q$. Several studies document an asymmetry between reaction to negative and positive earnings surprises (see Skinner and Sloan, 2002; Conrad et al., 2002). In order to capture this potential difference, we introduce the dummy variable SURPSIGN which takes the value of 1 if UE for firm $i$ in quarter $q$ is above the median UE for that quarter and 0 otherwise:

$$
|\mathrm{UE}|_{i, q}=\frac{\left|A_{\mathrm{NetProfit}_{i, q}}-A_{\mathrm{NetProfit}_{i, q-4}}\right|}{\text { MarketCap }_{i, q}} .
$$

KAP indicator. Starting from June 2009, all listed companies at the Borsa Istanbul are required to disclose material information including earnings reports through the online KAP. In order to analyze the impact of KAP on the informativeness of earnings releases, we introduce the dummy variable POST-KAP which takes the value of 1 for the period June 2009-May 2010 which we designate as the post-KAP period and 0 for the period June 2008-May 2009 which we designate as the pre-KAP period. Similar to Hung et al. (2015), our analysis is restricted to a 
one-year before KAP introduction and one-year after KAP introduction to reduce the effect of potentially confounding events.

Variables for firm characteristics. As noted in Landsman and Maydew (2002), an observed change in our information content proxies could be simply due to change in the composition of sample firms over time. In order to control for these changes, we introduce SIZE measured as the market value of equity in billions of US dollars at the end of quarter $q, B / M$ measured as the ratio of the quarter-end book value to market value of equity and BETA estimated from regressing daily stock returns on BIST-100 index returns for the non-announcement period of $[t-30, t-394]$. For the regression analysis, we use the logarithm of SIZE instead of SIZE as the distribution of the raw values of this variable is highly skewed.

\subsection{Sample selection and summary statistics}

We start with an initial sample of 16,061 observations for which earnings data are available from the local data vendor Rasyonet and announcement date data are available from Bloomberg for the fiscal quarters in the 2007-2017 period. Then, we apply the selection criteria below to reach our final full sample of 12,143 observations from 396 companies. To reduce the effect of outliers, we winsorize all the continuous variables at the top and bottom 1 percent of their quarterly distribution. To analyze the impact of the adoption of KAP on Jun 1, 2009, we select a sub-sample of 2,030 observations by requiring an observation to have an earnings announcement in Jun 2008-May 2010 period on top of the selection criteria below:

- we only include firms with fiscal year ending in December. More than 95 percent firms listed at Borsa Istanbul have fiscal year ending in December;

- we require market cap value and book value are available at the end of the quarter $t$ and require them to be greater than $\$ 5 \mathrm{~m}$ and non-negative, respectively; and

- there is at least 12 months of past return and volume data to compute AAR, AVOL and beta.

Table I presents descriptive statistics for the full sample used. The average values for the two information content proxies we employ are both significantly greater than 0 with average AVOL at 0.14 and average AAR at 0.28 . This points to an extensive market reaction and accordingly significant information content at earnings announcements. However, there is also significant variation in market reaction as AVOL and AAR are -0.40 at the 25 th percentile indicating that there is no positive abnormal market reaction to a significant part of the sample. The average observation in our sample has a firm size of $\$ 0.78 \mathrm{bn}$, a book-to-market ratio of 1.09 and an absolute unexpected earnings of 5 percent.

\begin{tabular}{|c|c|c|c|c|c|c|c|c|}
\hline & Mean & SD & 10th Pctl. & 25th Pctl. & 50th Pctl. & 75th Pctl. & 90th Pctl. & \\
\hline AVOL & 0.14 & 0.83 & -0.82 & -0.40 & 0.09 & 0.61 & 1.15 & \\
\hline AAR & 0.28 & 1.14 & -0.65 & -0.40 & -0.02 & 0.62 & 1.52 & \\
\hline ANDUM & 0.25 & 0.43 & 0.00 & 0.00 & 0.00 & 0.00 & 1.00 & \\
\hline SIZE & 0.78 & 2.07 & 0.01 & 0.03 & 0.11 & 0.41 & 1.64 & \\
\hline $\mathrm{B} / \mathrm{M}$ & 1.09 & 6.38 & 0.27 & 0.48 & 0.81 & 1.31 & 1.98 & \\
\hline BETA & 0.65 & 0.42 & 0.16 & 0.39 & 0.64 & 0.90 & 1.16 & \\
\hline$|\mathrm{UE}|$ & 0.05 & 0.09 & 0.00 & 0.01 & 0.02 & 0.05 & 0.12 & Table I. \\
\hline SURPRISE SIGN & 0.50 & 0.50 & 0.00 & 0.00 & 0.00 & 1.00 & 1.00 & Summary table for \\
\hline Observations & 12,143 & & & & & & & full sample \\
\hline
\end{tabular}

Informativeness of earnings announcements 
JCMS

3,2

184

\section{Results}

Figure 1 graphically illustrates a gradual increase in both AVOL and AAR at earnings announcements over the sample period of 2007-2017. In order to understand the dynamics behind this increase, we employ a regression-based approach similar to Landsman and Maydew (2002) and regress AVOL and AAR against the time trend variable, TIME, the annual earnings dummy, ANDUM and the interaction between this variable and TIME (see specifications at 3 below). The Columns 1 and 2 in Table II report the results of these regressions for which $T$-statistics are corrected for heteroskedasticity and serial correlation using the Huber-White maximum likelihood estimation procedure. The time trend coefficient for both AVOL and AAR regressions is significantly positive with $t$-statistics of 9.1 and 6.5 , respectively. This provides strong evidence that the information content of earnings as proxied by AVOL and AAR has increased over time in our sample period. On the other hand, the evidence on whether earnings informativeness is higher or lower for annual earnings announcements is mixed. The coefficient on ANDUM at Column 1 is positive and significant at the 1 percent level, while it is significantly negative at Column 2. Hence, AVOL is higher for annual earnings announcements, while AAR is lower. An interesting finding is that the coefficient on TIME $\times$ ANDUM at Column 1 is negative and significant at the 1 percent level indicating

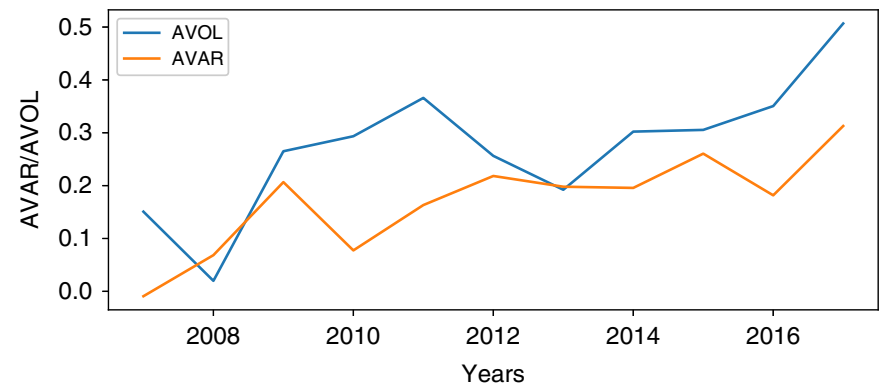

Figure 1.

AVOL and AVAR progression over the period 2007-2017
Table II.

Regression of AVOL and AVAR against time trend and firm characteristics for the period 2007-2017

\begin{tabular}{|c|c|c|c|c|}
\hline & $\begin{array}{c}(1) \\
\text { AVOL }\end{array}$ & $\begin{array}{c}(2) \\
\text { AAR }\end{array}$ & $\begin{array}{c}(3) \\
\text { AVOL }\end{array}$ & $\begin{array}{c}(4) \\
\text { AAR }\end{array}$ \\
\hline TIME & $0.00212^{* * * *}(9.10)$ & $0.00217 * * * *(6.50)$ & $0.00329 * * *(5.93)$ & $0.00209 * * * *(2.74)$ \\
\hline ANDUM & $0.280^{* * * *}(7.61)$ & $-0.137 * * *(-2.94)$ & $0.278 * * *(7.45)$ & $-0.0832 *(-1.78)$ \\
\hline TIME $\times$ ANDUM & $-0.00328 * * *(-7.14)$ & $0.000466(0.77)$ & $-0.00350 * * *(-7.55)$ & $-0.000338(-0.56)$ \\
\hline $\ln (\mathrm{SIZE})$ & & & $-0.0159 *(-1.80)$ & $0.00679(0.59)$ \\
\hline$B / M$ & & & $0.0594 * * *(3.84)$ & $0.0546 * * *(3.18)$ \\
\hline BETA & & & $0.0277(0.63)$ & $-0.311 * * *(-5.75)$ \\
\hline |UE| & & & $0.121(0.72)$ & $-0.230(-1.10)$ \\
\hline SURPRISE SIGN & & & $0.115^{* * *}(3.71)$ & $0.0490(1.16)$ \\
\hline TIME $\times \ln ($ SIZE $)$ & & & $0.000242^{* *}(2.23)$ & $0.000208(1.42)$ \\
\hline TIME $\times$ B/M & & & $-0.000704 * * *(-3.90)$ & $-0.000642^{* * * *}(-3.18)$ \\
\hline TIME $\times$ BETA & & & $-0.000751(-1.43)$ & $0.000662(1.02)$ \\
\hline TIME $\times|\mathrm{UE}|$ & & & $0.00650 * * *(2.66)$ & $0.0105 * * *(3.01)$ \\
\hline TIME $\times$ & & & & \\
\hline SURPRISE SIGN & & & $0.000665^{*}(1.66)$ & 0.000785 (1.39) \\
\hline Constant & $-0.0230(-1.29)$ & $0.152^{* * * *}(6.18)$ & $-0.198 * * *(-4.36)$ & $0.291 * * *(4.97)$ \\
\hline Observations & 12,143 & 12,143 & 12,143 & 12,143 \\
\hline
\end{tabular}

Notes: $t$-Statistics in parentheses. ${ }^{*} p<0.10 ; * * p<0.05 ; * * * p<0.01$ 
that the time trend in abnormal volatility is weaker for annual announcements compared to interim announcements. We obtain qualitatively similar results when we define AVOL and AAR using earnings announcement windows of $[-1,0]$ and $[0,1]$ rather than the $[-1,1]$ window utilized in this study.

The Columns 3 and 4 show the results when we add the variables IUEl, SURPSIGN, $\ln (\mathrm{SIZE})$, $B / M$ and BETA and interaction variables of these variables with TIME to the regression. The time trend coefficients for both AVOL and AAR remain significant at 1 percent level suggesting that the increase in the informativeness of earnings announcement is robust to the inclusion to a set of explanatory variables. The observation that the AVOL is higher, but AAR is lower for annual earnings announcements compared to interim earnings announcement also continues to hold true after adding control variables as evidenced by the significantly positive coefficient on ANDUM at Column 3 and significantly negative coefficient on the same variable at Column 4 . The negative coefficient on TIME $\times$ ANDUM at Column 3 confirms our finding that the time trend in AVOL is weaker for year-end announcements. Finally, for both AVOL and AAR the coefficients on TIME $\times B / M$ are significantly negative at the 1 percent level, while the coefficients on TIME $\times \mathrm{IUE}$ are significantly positive at the 1 percent level. We interpret these results as growth companies and earnings announcements with bigger absolute surprise having a more pronounced positive trend in the information content of earnings announcements:

$$
\mathrm{AVOL}=\alpha+\beta_{1} \mathrm{TIME}+\beta_{2} \mathrm{ANDUM}+\beta_{3} \mathrm{TIME} \times \mathrm{ANDUM}+\epsilon,
$$

$$
\mathrm{AAR}=\alpha+\beta_{1} \mathrm{TIME}+\beta_{2} \mathrm{ANDUM}+\beta_{3} \mathrm{TIME} \times \mathrm{ANDUM}+\epsilon .
$$

In order to analyze the impact of the introduction of the KAP on the informativeness of earnings announcements, we run the regressions at 4 below on the KAP sample. The significantly positive coefficients on the POST-KAP variable at Columns 2 and 4 show that the AAR is higher in the post-KAP period compared to pre-KAP period in both the specification without control variables as well as the specification with control variables. However, our results do not point to a similar positive change in AVOL due to KAP being made available as the coefficients on the POST-KAP are not significantly different from 0 at Columns 1 and 3. The adoption of KAP had a significant impact on the AAR around earnings announcements, but did not have a similar impact on the AVOL. Therefore, our findings provide only partial supportive evidence for the hypothesis that the earnings announcements garner higher market reaction with the improvement in the information dissemination technology with KAP (Table III):

$$
\begin{gathered}
\mathrm{AVOL}=\alpha+\beta_{1} \mathrm{POST}-\mathrm{KAP}+\beta_{2} \mathrm{ANDUM}+\beta_{3} \mathrm{POST}-\mathrm{KAP} \times \mathrm{ANDUM}+\epsilon, \\
\mathrm{AAR}=\alpha+\beta_{1} \mathrm{POST}-\mathrm{KAP}+\beta_{2} \mathrm{ANDUM}+\beta_{3} \mathrm{POST}-\mathrm{KAP} \times \mathrm{ANDUM}+\epsilon .
\end{gathered}
$$

\section{Conclusion}

In this paper, we study the informativeness of earnings announcements and its time trend in Borsa Istanbul using abnormal volume and abnormal absolute return as measures for information content. We show that earnings announcements are significant information events with both measures being significantly positive around the three-day window surrounding the earnings announcement. Furthermore, we find a positive time trend in informativeness which is most pronounced in growth companies and announcements with high absolute surprise. Analyzing interim earnings announcements in addition to annual earnings announcements allow us to observe how the information content of annual announcements compares to information content in interim announcements. We find higher 
JCMS

3,2 186
Table III.
Regression of AVOL
and AVAR against
adoption of KAP and
firm characteristics for the period 2008-2010

\begin{tabular}{|c|c|c|c|c|}
\hline & $\begin{array}{c}\text { (1) } \\
\text { AVOL }\end{array}$ & $\begin{array}{c}(2) \\
\text { AAR }\end{array}$ & $\begin{array}{c}\text { (3) } \\
\text { AVOL }\end{array}$ & $\begin{array}{c}(4) \\
\text { AAR }\end{array}$ \\
\hline POST-KAP & $-0.0183(-0.47)$ & $0.390 * * *(7.04)$ & $0.0494(0.42)$ & $0.344 * * *(2.64)$ \\
\hline ANDU & $0.241 * * *(3.84)$ & $0.0460(0.64)$ & $0.207 * * *(3.07)$ & $0.0354(0.45)$ \\
\hline POST-KAP $\times$ ANDUM & $-0.175 * *(-2.10)$ & $-0.414^{* * *}(-3.93)$ & $-0.124(-1.38)$ & $-0.381 * * *(-3.29)$ \\
\hline $\ln (\mathrm{SIZE})$ & & & $-0.0139(-0.86)$ & $0.0343^{* *}(2.13)$ \\
\hline$B / M$ & & & $0.0695^{* * * *}(2.91)$ & $0.0562 *(1.93)$ \\
\hline BETA & & & $0.0176(0.21)$ & $-0.250^{* * * *}(-3.24)$ \\
\hline IUEl & & & $-0.0458(-0.29)$ & $-0.157(-1.01)$ \\
\hline SURPRISE SIGN & & & $0.139 * * * *(2.63)$ & $0.133 * *(2.36)$ \\
\hline POST-KAP $\times \ln ($ SIZE $)$ & & & $0.0192(0.92)$ & $0.00291(0.10)$ \\
\hline $\mathrm{P} \times \mathrm{B} / \mathrm{M}$ & & & $0.00999(0.21)$ & $-0.0433(-0.58)$ \\
\hline POST-KAP $\times$ BETA & & & $-0.0932(-0.88)$ & $0.0752(0.69)$ \\
\hline POST-KAP $\times|\mathrm{IUE}|$ & & & $0.648(1.59)$ & $1.437 * *(2.42)$ \\
\hline POST-KAP $\times$ SURPRISE SIGN & & & $0.0305(0.43)$ & $-0.0655(-0.68)$ \\
\hline Constant & $0.170 * * *(5.89)$ & $0.0638 * *(2.20)$ & $-0.0331(-0.33)$ & $0.177 * *(2.07)$ \\
\hline Observations & 2,030 & 2,030 & 2,030 & 2,030 \\
\hline
\end{tabular}

AVOL, but lower AAR at annual earnings announcements which suggest that annual announcements are not strictly superior to interim announcements in terms of their informational value for investors. Finally, we examine the introduction of the online disclosure platform KAP as an improvement in information dissemination technology. We find an increase in AAR after the introduction of KAP, but no change in AVOL. We think a fruitful venue for further research could be conducting a comprehensive study to see which of the competing explanations such as increase in concurrent information, improvement in access to information or change in investor sophistication best explain the increasing informativeness of earnings announcements.

\section{References}

Asthana, S. and Balsam, S. (2001), "The effect of EDGAR on the market reaction to 10-K filings", Journal of Accounting and Public Policy, Vol. 20 Nos 4-5, pp. 349-372.

Bamber, L.S. (1986), "The information content of annual earnings releases: a trading volume approach", Journal of Accounting Research, Vol. 24 No. 1, pp. 40-56.

Bamber, L.S. (1987), "Unexpected earnings, firm size, and trading volume around quarterly earnings announcements”, Accounting Review, Vol. 62 No. 3, pp. 510-532.

Basu, S., Hwang, L. and Jan, C.-L. (2002), "Auditor conservatism and quarterly earnings”, working paper, Temple University, April, Philadelphia, PA.

Beaver, W.H. (1968), "The information content of annual earnings announcements", Journal of Accounting Research, Vol. 6 No. 67, pp. 67-92.

Collins, D.W., Li, O.Z. and Xie, H. (2009), "What drives the increased informativeness of earnings announcements over time?", Review of Accounting Studies, Vol. 14 No. 1, pp. 1-30.

Conrad, J., Cornell, B. and Landsman, W.R. (2002), “When is bad news really bad news?”, The Journal of Finance, Vol. 57 No. 6, pp. 2507-2532.

DeFond, M., Hung, M. and Trezevant, R. (2007), "Investor protection and the information content of annual earnings announcements: international evidence", Journal of Accounting and Economics, Vol. 43 No. 1, pp. 37-67.

Dellavigna, S. and Pollet, J.M. (2009), "Investor inattention and Friday earnings announcements", Journal of Finance, Vol. 64 No. 2, pp. 709-749. 
Francis, J., Schipper, K. and Vincent, L. (2002), "Earnings announcements and competing information", Journal of Accounting and Economics, Vol. 33 No. 3, pp. 313-342.

Gajewski, J.F. and Quéré, B.P. (2001), "The information content of earnings and turnover announcements in France", European Accounting Review, Vol. 10 No. 4, pp. 679-704.

Hung, M., Li, X. and Wang, S. (2015), "Post-earnings-announcement drift in global markets: evidence from an information shock", Review of Financial Studies, Vol. 28 No. 4, pp. 1242-1283.

Kiger, J.E. (1972), "An empirical investigation of NYSE volume and price reactions to the announcement of quarterly earnings", Journal of Accounting Research, Vol. 10 No. 1, pp. 113-128.

Kim, O. and Verrecchia, R.E. (1991), "Trading volume and price reactions to public announcements", Journal of Accounting Research, Vol. 29 No. 2, pp. 302-321.

Landsman, W.R. and Maydew, E.L. (2002), "Has the information content of quarterly earnings announcements declined in the past three decades?", Journal of Accounting Research, Vol. 40 No. 3, pp. 797-808.

Morse, D. (1981), "Price and trading volume reaction surrounding earnings announcements: a closer examination", Journal of Accounting Research, Vol. 19 No. 2, pp. 374-383.

Mugaloglu, Y. and Erdag, E. (2011), "The relationship between stock return volatility and public disclosure: the case of Istanbul Stock Exchange online public disclosure platform", Journal of Applied Economics and Business Research, Vol. 1 No. 2, pp. 93-102.

Odabasi, A. (1998), "Security returns reactions to earnings announcements: a case study on the Istanbul stock exchange", Bogazici Journal: Review of Social, Economic and Administrative Studies, Vol. 12 No. 2, pp. 3-19.

Pellicer, M.J.A. and Rees, W.P. (1999), "Regularities in the equity price response to earnings announcements in Spain”, European Accounting Review, Vol. 8 No. 4, pp. 585-607.

Rippington, F.A. and Taffler, R.J. (1995), "The information content of firm financial disclosures", Journal of Business Finance \& Accounting, Vol. 22 No. 3, pp. 345-362.

Skinner, D.J. and Sloan, R.G. (2002), “Earnings surprises, growth expectations, and stock returns or don't let an earnings torpedo sink your portfolio", Review of Accounting Studies, Vol. 7 No. 2, pp. 289-312.

Sponholtz, C. (2008), "The information content of earnings announcements in Denmark", International Journal of Managerial Finance, Vol. 4 No. 1, pp. 4-36.

Truong, C. (2012), "Information content of earnings announcements in the New Zealand equity market, a longitudinal analysis", Accounting \& Finance, Vol. 52 No. s1, pp. 403-432.

Ziebart, D.A. (1990), "The trading association of activity between and consensus beliefs surrounding earnings announcements", The Accounting Review, Vol. 65 No. 2, pp. 477-488.

\section{Corresponding author}

Aykut Ahlatcioglu can be contacted at: aykutahlatcioglu@gmail.com

\section{Informativeness of earnings announcements}

For instructions on how to order reprints of this article, please visit our website:

www.emeraldgrouppublishing.com/licensing/reprints.htm

Or contact us for further details: permissions@emeraldinsight.com 